REVISTA DE DERECHO UNED, núm. 5, 2009

\title{
LOS PROCEDIMIENTOS ADMINISTRATIVOS EN MATERIA DE TRANSFERENCIAS INTERNACIONALES DE DATOS DE CARÁCTER PERSONAL
}

\author{
PEDRo M. ARENAS NAON \\ Técnico. Dirección de Regulación de Operadores, \\ Comisión del Mercado de las Telecomunicaciones
}

Resumen: Este artículo tiene por objeto el análisis de los procedimientos administrativos en materia de transferencias internacionales de datos de carácter personal. Estos procedimientos se encuentran sometidos (además de a las reglas generales de los procedimientos administrativos) a determinadas reglas especiales, contenidas en los artículos 137 a 144 del Reglamento de desarrollo de la Ley Orgánica de protección de datos de carácter personal. ¿Qué valoración merece esta regulación especial? ¿Se ha enfrentado a las particularidades de la materia y las ha regulado con el alcance y precisión exigidos?

Para responder a tales preguntas, el artículo trata, en particular: (a) qué normas son aplicables a los procedimientos relacionados con las transferencias internacionales de datos personales, (b) el procedimiento de autorización de transferencias internacionales (incluida su iniciación, instrucción y terminación), (c) las cuestiones procedimentales relativas a la autorización de trasferencias internacionales sobre la base de «reglas corporativas vinculantes», y (d) el procedimiento de suspensión de transferencias internacionales, incluido el procedimiento para el levantamiento de la suspensión.

Palabras clave: Protección de datos, datos de carácter personal, transferencias internacionales, procedimientos administrativos, reglas corporativas vinculantes, autorización, suspensión. 
Abstract: The purpose of this article is to analyse the proceedings before the Spanish data protection authority in connection with the international transfers of personal data. These proceedings are subject (in addition to the general rules for administrative proceedings) to certain specific rules, established in Articles 137 to 144 of the Spanish Data Protection Regulation. ¿How should we value these specific rules? ¿Have they duly addressed the peculiarities of international transfers of personal data from a procedural perspective?

In order to answer these questions, the article analyses, in particular: (a) what statutes apply to the proceedings in connection with the international transfers of personal data, (b) the proceedings to authorise international transfers of personal data (including their start, investigation and termination), (c) the procedural questions related to the authorisation of international transfers on the basis of binding corporate rules, and (d) the proceedings to suspend international transfers, including the proceeding to lift that suspension.

Key words: Data protection, personal data, international transfers, administrative proceedings, binding corporate rules, authorisation, suspension.

Sumario: I. Introducción. Delimitación del objeto de análisis.II. Régimen aplicable a los procedimientos relacionados con las transferencias internacionales de datos.-III. Procedimiento de autorización de las transferencias internacionales de datos.-III.1. Objeto del procedimiento.-III.2. Iniciación; A) Legitimación para iniciar el procedimiento; B) Contenido y documentación a aportar con la solicitud; C) Especial consideración a la documentación de la solicitud que acredite «el cumplimiento de los requisitos legales necesarios para la realización de la transferencia, en su caso».-III.3. Instrucción del procedimiento. En particular, el período de información pública y la confidencialidad de documentación del expediente.-III.4. Terminación del procedimiento.-IV. Las reglas corporativas vinculantes del artículo 70.4 del Reglamento.-IV.1. Introducción: las reglas corporativas vinculantes.-IV.2. Resumen del procedimiento de aprobación de las reglas corporativas vinculantes en los documentos de trabajo del Grupo 29.-IV.3. Postura de la AEPD y Reglamento en relación con el procedimiento de las reglas corporativas vinculantes.-IV.4. Conclusión.-V. Procedimiento de suspensión temporal de transferencias internacionales de datos.-V.1. Objeto del procedimiento.V.2. Iniciación.-V.3. Instrucción y resolución.-V.4 Levantamiento de la suspensión temporal.-VI. Inscripción en el Registro General de Protección de Datos.-VII. Notificaciones exigidas por la normativa co- 
munitaria.-VIII. Recursos contra las Resoluciones.-IX. Conclusión. Bibliografía.

\section{INTRODUCCIÓN. DELIMITACIÓN DEL OBJETO DE ANÁLISIS}

Este artículo tiene por objeto el análisis de los procedimientos administrativos en materia de transferencias internacionales de datos de carácter personal. Estos procedimientos se encuentran regulados en los artículos 137 a 144 del Real Decreto 1720/2007, de 21 de diciembre, por el que se aprueba el Reglamento de desarrollo de la Ley Orgánica 15/1999, de 13 de diciembre, de protección de datos de carácter personal (en adelante, el «Reglamento»), que forman el Capítulo V («Procedimientos relacionados con las transferencias internacionales de datos») del Título IX del Reglamento ( Procedimientos tramitados por la Agencia Española de Protección de Datos»). Estos procedimientos consisten en el procedimiento de autorización de transferencias internacionales de datos de carácter personal y el procedimiento para su suspensión temporal, incluido el procedimiento para el levantamiento de tal suspensión.

Como se ha indicado, este artículo hace referencia a aspectos procedimentales de las transferencias internacionales, no materiales (sobre el fondo). Los aspectos materiales de la normativa de protección de datos y Reglamento en materia de transferencias internacionales no son objeto de este artículo ${ }^{1}$.

El procedimiento tiene una importancia de primer orden respecto de la actuación de la Administración, en cuanto garantía de la posición jurídica de los administrados (en este caso, en particular, de los exportadores de datos de carácter personal y los afectados) ${ }^{2}$.

1 Para un buen resumen y análisis del régimen sustantivo de las transferencias internacionales de datos de carácter personal, véase ÁLVAREZ RIGAUDÍAS, C., Transferencias Internacionales de Datos en AAVV, Comentarios al Reglamento de Desarrollo de la Ley Orgánica 15/1999, de 13 de diciembre, de Protección de Datos de Carácter Personal (Aprobado por RD 1720/2007, de 21 de diciembre), Thomson Civitas, Cizur Menor, 2008, págs. 499 y siguientes.

2 «El procedimiento administrativo es la primera de esas garantías [de la posición jurídica del administrado], en tanto que supone que la actividad de la Administración tiene que canalizarse obligadamente a través de unos cauces determinados como requisito mínimo para que pueda calificarse de legítima.» (GARCÍA DE ENTERRÍA, E. Y FERNÁNDEZ, T.R., Curso de Derecho Administrativo, Volumen II, Décima Edición, Thomson-Civitas, Cizur Menor, Navarra, página 454). Además de esta función de garantía del procedimiento, los mismos autores destacan «su triple dimensión de vehículo de participación de los administrados en la elaboración de las decisiones administrativas, de 
Como manifestación y garantía del sometimiento de nuestra Administración a la ley y al Derecho (proclamado en el artículo 103 de la Constitución), el artículo 53 LRJPAC ordena que la producción de los actos administrativos se ajuste al procedimiento establecido.

En este contexto, el Reglamento ha optado por establecer determinadas reglas especiales en relación con los procedimientos administrativos sobre transferencias internacionales de datos de carácter personal, reglas que han de completarse con las reglas establecidas con carácter general para los procedimientos administrativos en la LRJPAC: «... se ha optado por normar exclusivamente aquellas especialidades que diferencian a los distintos procedimientos tramitados por la Agencia de las normas generales previstas para los procedimientos en la Ley 30/1992, de 26 de noviembre, de Régimen Jurídico de las Administraciones Públicas y Procedimiento Administrativo Común, cuya aplicación se declara supletoria al presente Reglamento» (Exposición de Motivos del Reglamento).

El esquema que se seguirá es el siguiente: (a) en el apartado II, se tratará del régimen aplicable a los procedimientos relacionados con las transferencias internacionales, (b) en el apartado III, se describirá el procedimiento de autorización de transferencias internacionales (incluida su iniciación, instrucción — con especial consideración a la información sensible y al trámite de información pública- y terminación), (c) en el apartado IV, se tratarán las cuestiones procedimentales relativas a la autorización de trasferencias internacionales sobre la base de reglas corporativas vinculantes (cuestión que se ha desgajado del apartado anterior debido a su complejidad y extensión), (d) en el apartado V, se describirá el procedimiento de suspensión de transferencias internacionales, incluido el procedimiento para el levantamiento de la suspensión, (e) en los apartados VI a VIII, se tratarán determinadas cuestiones comunes a todos los procedimientos (la inscripción de la Resolución correspondiente en el Registro General de Protección de Datos, las notificaciones exigidas por la normativa comunitaria y, muy brevemente, los recursos disponibles frente a las Resoluciones).

mecanismo de garantía de los derechos de los particulares y de cauce para la pronta y eficaz satisfacción de los intereses generales» (idem, pág. 475). 


\section{RÉGIMEN APLICABLE A LOS PROCEDIMIENTOS RELACIONADOS CON LAS TRANSFERENCIAS INTERNACIONALES DE DATOS}

El Reglamento ha optado por establecer varias reglas especiales en relación con los procedimientos tramitados ante la Agencia Española de Protección de Datos -AEPD - (en su Título IX) y, dentro de éstas, reglas aplicables a todos estos procedimientos (i.e., los artículos 115 y 116) y reglas relativas a determinados procedimientos en materia de transferencias internacionales, contenidas en los artículos 137 a 144 del Reglamento, ambos inclusive.

Estas reglas especiales han de interpretarse y aplicarse en el marco de nuestro ordenamiento administrativo y de las reglas generales que éste establece para los procedimientos administrativos y, en particular, de conformidad con las disposiciones comunes y garantías que, respecto de los procedimientos administrativos, establece la LRJPAC.

En efecto y tal y como señala expresamente el artículo 35 LOPD $^{3}$, la AEPD actuará en el ejercicio de sus funciones públicas sometida a la LRJPAC y estas funciones incluyen, en particular, la concesión de autorizaciones para las transferencias internacionales de datos de carácter personal ${ }^{4}$. Por su parte, la LRJPAC somete a su ámbito de aplicación las "Administraciones Públicas», que incluyen las Entidades de Derecho Público con personalidad jurídica propia, vinculadas a la Administración General del Estado, como es el caso de la $\mathrm{AEPD}^{5}$.

Por ello, la aplicación de las normas especiales procedimentales del Reglamento ha de completarse, para lo no previsto en éstas, por las contenidas en la LRJPAC ${ }^{6}$. En este sentido, la Exposición de Mo-

${ }^{3} \mathrm{El}$ artículo 35.2 LOPD establece que: «En el ejercicio de sus funciones públicas, y en defecto de lo que disponga la presente Ley y sus disposiciones de desarrollo, la Agencia Española de Protección de Datos actuará de conformidad con la Ley 30/1992, de 26 de noviembre, de Régimen Jurídico de las Administraciones Públicas y del Procedimiento Administrativo Común. En sus adquisiciones patrimoniales y contratación estará sujeta al Derecho privado».

${ }^{4}$ Las funciones de la AEPD aparecen listadas en el artículo 37 LOPD e incluyen, en particular, «ejercer el control y adoptar las autorizaciones que procedan en relación con los movimientos internacionales de datos, así como desempeñar las funciones de cooperación internacional en materia de protección de datos personales».

$5 \mathrm{Vid}$. artículo 2 LRJPAC.

6 En particular, por las «disposiciones generales sobre los procedimientos administrativos» contenidas en el Título VI de la LRJPAC. 
tivos y el artículo 115 del Reglamento declaran la LRJPAC de aplicación supletoria a las normas del Reglamento sobre procedimientos tramitados ante la AEPD y, por tanto, también a los procedimientos relativos a las transferencias internacionales ${ }^{7}$.

En conclusión, los procedimientos relativos a las transferencias internacionales regulados por el Reglamento se regirán por el Título IX del Reglamento (esto es, por las disposiciones generales contenidas en su Capítulo I - artículos 115 y 116- y por las disposiciones sobre procedimientos relacionados con transferencias internacionales —artículos 137 y 144-) y, supletoriamente, por la LRJPAC.

Sin perjuicio de lo anterior y aunque el Reglamento no lo recuerde expresamente, no queremos dejar de señalar que las disposiciones especiales procedimentales del Reglamento habrán de respetar en cualquier caso las garantías mínimas de los ciudadanos respecto de la actividad administrativa establecidas en la LRJPAC (por ejemplo, el artículo 42 de la LRJPAC — tras su reforma por la Ley 4/1999, de 13 de enero- establece un límite en relación con el plazo máximo que las normas reglamentarias reguladoras de los procedimientos administrativos especiales puedan prever en relación con la duración de los procedimientos) ${ }^{8}$.

\section{PROCEDIMIENTO DE AUTORIZACIÓN DE LAS TRANSFERENCIAS INTERNACIONALES DE DATOS}

Los artículos 137 a 140 del Reglamento (ambos inclusive) conforman, junto a la normativa supletoria de la LRJPAC, el procedimiento que ha de seguir la AEPD para la autorización o denegación de transferencias internacionales.

7 El artículo 115 del Reglamento establece que: «1. Los procedimientos tramitados por la Agencia Española de Protección de Datos se regirán por lo dispuesto en el presente Título, y supletoriamente, por la Ley 30/1992, de 26 de noviembre, de Régimen Jurídico de las Administraciones Públicas y del Procedimiento Administrativo Común. 2. Específicamente serán de aplicación las normas reguladoras del procedimiento administrativo común al régimen de representación en los citados procedimientos».

8 El apartado 2 de la Exposición de Motivos de la Ley 30/1992 indica que: «La Ley recoge esta concepción constitucional de distribución de competencias y regula el procedimiento administrativo común, de aplicación general a todas las Administraciones Públicas y fija las garantías mínimas de los ciudadanos respecto de la actividad administrativa. Esta regulación no agota las competencias estatales o autonómicas de establecer procedimientos específicos ratione materiae que deberán respetar, en todo caso, estas garantías». 
La Memoria de la AEPD de 2008 indica que el número de expedientes de autorización que se iniciaron tal año ascendió a 137 y destaca su aumento respecto de años anteriores ${ }^{9}$.

\section{III.1. Objeto del procedimiento}

El objeto del procedimiento es la obtención de la autorización previa que, en determinados supuestos, es necesaria para realizar una transferencia internacional (véanse los artículos 33 y 34 LOPD) ${ }^{10}$.

Nótese que no es necesario solicitar autorización para las transferencias internacionales previstas en el artículo 34 LOPD y, en particular, para las que tengan como destino un país de la Unión Europea o respecto del cual se haya declarado que garantiza un nivel de protección adecuado en materia de protección de datos.

\section{III.2. Iniciación}

Como se desarrolla a continuación, el procedimiento se inicia por el exportador que ha de consignar en su solicitud determinada información y documentación.

\section{A) Legitimación para iniciar el procedimiento}

De conformidad con el artículo 137 del Reglamento, el procedimiento para la obtención de la autorización para las transferencias internacionales se iniciará «siempre a solicitud del exportador que pretenda llevar a cabo la transferencia».

Por tanto, el Reglamento impone la carga de solicitar la correspondiente autorización al exportador de los datos de carácter perso-

9 Memoria de la AEPD de 2008, pág. 75.

${ }_{10}$ Tal y como señala López-Lapuente «... las transferencias internacionales que requieren la autorización previa del Director de la AEPD son aquellas con destino a terceros países que no proporcionan un nivel de protección «adecuado» o «equiparable» y que además no quedan exceptuadas de la autorización de acuerdo con los apartados a) a j) del artículo 34 de la LOPD». Véase LÓPEZ-LAPUENTE, L., Procedimientos relacionados con las transferencias internacionales de datos en AAVV, Comentarios al Reglamento de Desarrollo de la Ley Orgánica 15/1999, de 13 de diciembre, de Protección de Datos de Carácter Personal (Aprobado por RD 1720/2007, de 21 de diciembre), Thomson Civitas, Cizur Menor, 2008, pág. 825. 
nal y parece excluir que el procedimiento se pueda iniciar a instancia de cualesquiera otras partes como, por ejemplo, los importadores.

Esta opción del Reglamento es respetuosa con la LOPD, pues esta Ley Orgánica no especifica expresamente quién (importador o exportador) habrá de solicitar la autorización para la transferencia internacional. Por otra parte, es probable que el exportador de los datos tenga más nexos con España que el importador (ubicado, en principio, fuera de España), por lo que la opción de imponer en cualquier caso la carga al exportador parece ofrecer ventajas prácticas en relación con la tramitación del expediente de autorización y el control de su cumplimiento. Finalmente, para que los datos sean efectivamente exportados y lleguen al importador es necesario una iniciativa previa del exportador, consistente en la puesta a disposición del importador de los datos personales. Por todo ello, la opción del Reglamento, que establece la carga de solicitar la autorización sobre el exportador parece plenamente justificada sin perjuicio, obviamente, de que el importador pueda ostentar la condición de interesado a efectos del procedimiento (en virtud del artículo 31 de la LRJPAC) e intervenir en éste en tal calidad. ${ }^{11}$

Exportador es «la persona física o jurídica, pública o privada, u órgano administrativo que realice, conforme a lo dispuesto en el presente Reglamento, una transferencia de datos de carácter personal a un país tercero $»^{12}$.

La citada definición no especifica expresamente si sólo el responsable del fichero tiene la condición de exportador o si también podrían alcanzar tal condición sus encargados de tratamiento (a diferencia de la definición de "transmitente»-equivalente del exportador-que contenía la Instrucción 1/2000, que sí especificaba expresamente la condición de responsable del «transmitente») ${ }^{13}$.

Desde nuestro punto de vista, la falta de mención a la condición de responsable del exportador no conlleva que sus encargados (cuando limiten su tratamiento a las instrucciones del responsable, en virtud del artículo 12 LOPD, y realicen la transferencia internacional de

11 En el mismo sentido, LÓPEZ-LAPUENTE, L., op. cit., pág. 826.

12 Vid. el artículo 5.j) del Reglamento.

13 La Instrucción 1/2000, de 1 de diciembre de la AEPD no utilizaba el concepto de «exportador» sino el de «transmitente», que definía en su Norma Primera como «la persona física o jurídica, pública o privada, responsable del fichero o del tratamiento de los datos de carácter personal que son objeto de transferencia internacional, y por destinatario la persona física o jurídica, pública o privada, situada fuera del territorio español que recibe los datos transmitidos». 
conformidad con estas instrucciones) también puedan ser calificados de «exportadores». En efecto, si el «encargado» ha de actuar bajo las instrucciones del responsable (lo cual será siempre el caso, por definición, en la teoría de las figuras encargados / responsables), el que realiza la transferencia $-\mathrm{O}$, al menos, el que decida sobre ésta y por tanto le es imputable desde un punto de vista jurídico- siempre será el responsable del fichero. En consecuencia, el responsable del fichero será quien esté obligado (y legitimado) para solicitar la autorización de la transferencia internacional.

Caso distinto es que el encargado no respete las instrucciones del responsable del fichero y realice, por sí mismo y sin instrucciones del responsable, la transferencia internacional. Pues bien, en tal caso y de conformidad con el artículo 12.4 LOPD, tal encargado habrá de considerarse responsable del fichero a todos los efectos y, por tanto, exportador, en el caso de que realice la transferencia internacional. ${ }^{14} \mathrm{En}$ consecuencia, en tales casos, el encargado no resulta obligado a las obligaciones del exportador en cuanto encargado, sino en su condición de responsable.

Otro caso distinto, asimismo, lo constituirá el supuesto en que el responsable del fichero solicite al encargado que asuma, entre los servicios que le preste, la solicitud de autorización para la transferencia internacional. En tal caso, la solicitud se haría por el encargado, pero en nombre y por cuenta del responsable del fichero (que conservaría por tanto su carácter de exportador de los datos) y la representación del responsable por el encargado exigiría poder especial concedido por el responsable al encargado a estos efectos.

En conclusión, el «exportador» —esto es, el responsable del fichero de los datos personales que se van a transferir- es el único legitimado para iniciar, mediante la correspondiente solicitud, el procedimiento para la autorización de la transferencia internacional.

\section{B) Contenido y documentación a aportar con la solicitud}

De conformidad con el artículo 137 del Reglamento, la solicitud habrá de acompañarse de la siguiente información o documentación:

${ }^{14} \mathrm{El}$ artículo 12.4 LOPD señala que: «En el caso de que el encargado del tratamiento destine los datos a otra finalidad, los comunique o los utilice incumpliendo las estipulaciones del contrato, será considerado también responsable del tratamiento, respondiendo de las infracciones en que hubiera incurrido personalmente.» 
(a) la identificación del fichero (o ficheros) a cuyos datos se refiera la transferencia internacional, con indicación de su denominación y código de inscripción en el Registro General de Protección de Datos.

Esta exigencia conlleva la obligación de notificar el fichero correspondiente antes de solicitar la autorización para la transferencia internacional de los datos personales contenidos en éste.

(b) la indicación de la transferencia o transferencias respecto de las que se solicita la autorización, con indicación de la finalidad que la justifica.

La indicación de la finalidad de la transferencia es un dato ineludible pues sólo a la vista de ésta puede analizarse en qué medida la transferencia internacional cumple con los requisitos y principios que, para la realización de transferencias internacionales, establece nuestro ordenamiento jurídico.

(c) la «documentación que incorpore las garantías exigibles para la obtención de la autorización». Tal y como señalan los párrafos siguientes del artículo 137 del Reglamento, esta documentación será la siguiente:

(i) Cuando la solicitud de autorización se fundamente en un contrato entre el exportador e importador de datos, la documentación a aportar consistirá en una "copia del contrato» y la documentación que acredite «la concurrencia de poder suficiente en sus otorgantes».

En la práctica y respecto del contrato, los solicitantes utilizan en la mayoría de los casos (sino en todos), las cláusulas contractuales tipo aprobadas por la Comisión Europea ${ }^{15}$.

En relación con la copia del contrato, el Reglamento no especifica qué tipo de copia se requiere por lo que, en lógica, parece lógico entender que cualquier tipo de copia es suficiente y que, desde luego, no es necesario el original. Aún cuando las Resoluciones de la AEPD no

15 La Memoria de la AEPD del ejercicio 2006 destaca en sus páginas 46 y 47 la utilización en la mayoría de los supuestos de las cláusulas contractuales tipo de la Decisión de la Comisión 2002/16/CE de las Comunidades Europeas, de 27 de diciembre de 2001, relativa a las cláusulas contractuales tipo para la transferencia internacional de datos personales a los encargados del tratamiento establecidos en terceros países y, en el resto de los supuestos, de las de la Decisión de la Comisión 2001/497/CE de las Comunidades Europeas, de 15 de junio de 2001, relativa a las cláusulas tipo para la transferencia de datos personales a un tercer país de conformidad con la Directiva 95/46/CE, modificada por la Decisión de la Comisión 2004/915/CE de las Comunidades Europeas, de 27 de diciembre de 2004. 
especifiquen en muchos casos en sus Antecedentes si el solicitante aporta un original o una copia (y, dentro de las copias, qué tipo de copia), parece que la práctica generalizada es aportar los contratos originales ${ }^{16}$, pues existen supuestos en que la AEPD ha solicitado expresamente el original del contrato ${ }^{17}$. Sin perjuicio de lo anterior, también parecen existir casos en que la AEPD ha aceptado traducciones juradas al castellano de los contratos en vez de éstos ${ }^{18}$.

$\mathrm{Al}$ referirse a la documentación que acredite «la concurrencia de poder suficiente en sus otorgantes», el Reglamento está regulando los supuestos en que los contratos correspondientes se otorguen por representantes debidamente apoderados (será el caso, por ejemplo, de los supuestos en que el exportador o importador sean personas jurídicas en vez de físicas). Esta documentación podrá consistir por tanto en cualquier documentación apta para acreditar las facultades del firmante.

En la práctica, esta documentación consistirá en general en una escritura de poder otorgada por la sociedad correspondiente al firmante o en una escritura en que conste un cargo del firmante suficiente a efectos de representar a la sociedad (p.ej., de acuerdo con el derecho societario español, el cargo de administrador solidario). La AEPD ha admitido fotocopias de las escrituras de poder ${ }^{19}$.

En el caso de que alguna de las sociedades en cuestión fuera extranjera, será necesario que los poderes se acompañen de un certificado que acredite la representación (pues se trata de una cuestión sometida a derecho extranjero, que la AEPD no ha de conocer), con la apostilla de la Haya.

(ii) La fundamentación de la solicitud de autorización de transferencia internacional en las reglas corporativas vinculantes del artículo 70.4 del Reglamento conlleva una problemática particular que se tratará en el apartado 4 de este artículo.

(d) la documentación relativa al «cumplimiento de los requisitos legales necesarios para la realización de la transferencia, en su caso» (sobre este particular, véase el siguiente apartado C).

(e) finalmente, el artículo 137 del Reglamento señala que la información y documentación que identifica a efectos de su aporta-

\footnotetext{
16 Vid. e.g., Res. AEPD TI/00043/2007, TI/00004/2007 y TI/00003/2007.

17 Vid. Res. AEPD TI/00027/2006.

18 Vid. e.g., Res. AEPD TI/00052/2006.

19 Vid. e.g., Res. AEPD TI/00052/2006.
} 
ción junto a la solicitud, lo es «además de los requisitos legalmente exigidos».

Desde nuestro punto de vista, el Reglamento se refiere con la expresión «además de los requisitos legalmente exigidos» al contenido que, para las solicitudes y con carácter general, exige el artículo 70 LRJPAC, esto es, el siguiente contenido: (i) el nombre y apellidos del interesado (i.e., el exportador) o su denominación social y, en su caso, de la persona que lo represente, así como la identificación del medio preferente o del lugar que se señale a efectos de notificaciones, (ii) los hechos, razones y petición en que se concrete, con toda claridad, la solicitud (i.e., la autorización de la transferencia internacional, identificada de conformidad con las menciones exigidas en el artículo 137 del Reglamento), (c) el lugar y fecha, (d) la firma del solicitante o acreditación de la autenticidad de su voluntad expresada por cualquier medio, y (e) el órgano, centro o unidad administrativa a la que se dirige (i.e., la AEPD).

C) Especial consideración a la documentación de la solicitud que acredite "el cumplimiento de los requisitos legales necesarios para la realización de la transferencia, en su caso».

Como se ha señalado, el artículo 137 del Reglamento obliga al solicitante a acreditar en la solicitud de autorización de la transferencia internacional «el cumplimiento de los requisitos legales necesarios para la realización de la transferencia, en su caso", obligación que causa serias dudas en relación con su alcance (sobre todo a la vista de las consideraciones de la AEPD que veremos) ${ }^{20}$.

Desde una interpretación lógica de tal precepto, los «requisitos legales necesarios para la realización de la transferencia» no han de coincidir con «las garantías exigibles para la obtención de la autorización» de la transferencia internacional (pues la letra c del artículo 137.2 del Reglamento distingue aquellos requisitos de estas garantías). Siendo las garantías adecuadas el único presupuesto legal para la concesión de la autorización, ¿qué requisitos ha de acreditar el solicitante distintos de éstas?

20 Véase LÓPEZ-LAPUENTE, L., op. cit., pág. 828: «Si la intención de este segundo inciso era la de facilitar al solicitante-exportador la preparación y presentación de su solicitud de autorización, lo adecuado hubiera sido incluir un listado lo más exhaustivo posible y evitar en cualquier caso remisiones genéricas a normas no identificadas expresamente». 
Si recurrimos a una interpretación auténtica del artículo 137 del Reglamento, que indague la voluntad de la Administración al aprobar el Reglamento, puede resultar indicativa del posible objeto de la norma la Referencia del Consejo de Ministros de 21 de diciembre de 2007, que señala que:

«Teniendo en cuenta las sensibilidades que se pudieran dar en la transferencia internacional de datos, sobre todo cuando pueda implicar la deslocalización de servicios prestados en territorio español, se incluirá un procedimiento de autorización de un trámite de información pública, donde se podrán aportar alegaciones sobre la legalidad de estas actuaciones».

En su justificación del trámite de información pública (que trataremos en el apartado 3.3 de este artículo), el Gobierno parece indicar que la legalidad de la transferencia internacional pudiera estar afectada por la deslocalización de servicios que fueran prestados hasta la fecha en territorio español. Esta vinculación de la legalidad de la transferencia internacional a la oportunidad de eventuales deslocalizaciones, junto a la obligación del exportador de acreditar en su solicitud los «requisitos legales necesarios para la realización de la transferencia», podría indicar, hipotéticamente, que la Administración pretende mediante el régimen establecido en el Reglamento que el solicitante acredite a la AEPD la legalidad de la deslocalización y la AEPD enjuicie ésta. Tal conclusión supondría una flagrante extralimitación de las funciones que nuestro ordenamiento tiene encomendadas a la AEPD, por lo que, en principio, parece que habría de descartarse.

Sin perjuicio de lo anterior, la AEPD (que ha trabajado muy activamente en la preparación del Reglamento y para su aprobación) parece tener en mente también las trasferencias de datos de trabajadores cuando se refiere al «cumplimiento de los requisitos legales necesarios para la realización de la transferencia, en su caso ${ }^{21}$.

${ }^{21}$ En efecto, la AEPD señala en su Informe sobre transferencias internacionales de datos, Inspección sectorial de oficio España-Colombia en centros de atención al cliente, julio de 2007, lo siguiente: «Como condición previa a la realización de una transferencia internacional de datos el exportador de los datos debe cumplir con el resto de obligaciones que establece la normativa de protección de datos, y cualquiera otra que pudiera resultar de aplicación. Un caso paradigmático se da cuando la transferencia de datos puede afectar a otros derechos de los trabajadores. En este caso se deberá tener en cuenta el cumplimiento de las obligaciones relacionadas con el derecho laboral y, en particular, la obligación de informar al comité de empresa de acuerdo con el art. 42.4 del Estatuto de los Trabajadores (RDL 1/1995, de 24 de marzo) en relación con la transposición de la Directiva 2002/14/CE, por la que se establece un marco general relativo a la información y a la consulta de los trabajadores en la Comunidad Europea». 
Esta aparente voluntad del Gobierno y de la AEPD de instrumentalizar la normativa de protección de datos para asegurar el cumplimiento de la normativa laboral nos parece muy criticable.

En efecto, la AEPD estaría conociendo de cuestiones que son totalmente ajenas a su ámbito competencial ${ }^{22}$ y sobre las que es difícil que tenga conocimientos técnicos, como son las cuestiones de derecho laboral. Por otro lado, el control por la AEPD de las transferencias internacionales está acotado por la LOPD y la Directiva 95/46/CE 23 y no parece legítimo extenderlo a cuestiones ajenas al cumplimiento de las garantías de la transferencia internacional. La existencia de límites al control por la AEPD de las transferencias internacionales ya fueron recordados a ésta por la Audiencia Nacional (Sala de lo Contencioso-Administrativo, Sección Primera) en su sentencia de 15 de marzo de $2002^{24}$ (prohibiendo a la AEPD extender su control a las transferencias internacionales del artículo 34 LOPD, a través de la Instrucción 1/2000).

Finalmente, es de señalar en relación con «el cumplimiento de los requisitos legales necesarios para la realización de la transferencia, en su caso», que la AEPD viene incluyendo en todas sus Resoluciones de autorización de transferencias internacionales un último apartado, bajo el epígrafe «en cuanto al cumplimiento de lo dispuesto en la Ley Orgánica 15/1999», en el que trata distintas cuestiones relacionadas con el tratamiento de datos que hace el exportador. Asimismo, no es infrecuente que la AEPD aproveche la solicitud de autorización para exigir al exportador la notificación del nivel de seguridad aplicable en relación con los ficheros que fueron notificados cuando tal extremo no era exigido en la notificación del fichero ${ }^{25}$.

Ese control del cumplimiento de cuestiones legales ajenas a la transferencia internacional, con ocasión de la solicitud de autorización, también nos parece exorbitante, pues la tramitación de un pro-

${ }^{22}$ En el mismo sentido, véase a LÓPEZ-LAPUENTE, L., op. cit., pág. 829: «... cabe cuestionarse la legitimidad de la competencia de la AEPD para evaluar el cumplimiento o incumplimiento por exportador e importador de estas cuestiones ajenas a las normativa de protección de datos».

${ }^{23}$ De conformidad con el artículo 26.4 de la Directiva 95/46/CE: «Cuando la Comisión decida, según el procedimiento establecido en el apartado 2 del artículo 31, que determinadas cláusulas contractuales tipo ofrecen las garantías suficientes establecidas en el apartado 2, los Estados miembros adoptarán las medidas necesarias para ajustarse a la decisión de la Comisión».

${ }^{24}$ Confirmada por la sentencia del Tribunal Supremo (Sala de lo Contencioso-Administrativo, Sección Sexta) de 25 de septiembre de 2006.

25 Vid., e.g., Res. AEPD TI/00042/2007. 
cedimiento de autorización de una transferencia internacional no debería convertirse en una excusa para la AEPD para revisar las circunstancias generales del tratamiento del fichero correspondiente.

\section{III.3. Instrucción del procedimiento. En particular, el período de información pública y la confidencialidad de documentación del expediente}

En relación con la instrucción del procedimiento, el aspecto más reseñable que aporta el Reglamento es la mención expresa en su artículo 138.1 a la posibilidad de la AEPD de abrir un período de información pública. Ello se corresponde con la práctica de la AEPD que tiene lugar, a nuestro conocimiento, desde las Resoluciones de junio de 2007 y conforme a la cual ésta viene abriendo períodos de información pública en relación con todos los procedimientos de autorización de transferencias internacionales ${ }^{26}$.

En relación con el período de información pública, el Reglamento se limita a una remisión al artículo 86.1 LRJPAC, que contiene la regulación general de este trámite ${ }^{27}$. A la vista de tal remisión, cabe destacar lo siguiente:

(a) El Reglamento (a diferencia de otra normativa sectorial ${ }^{28}$ ) no impone con carácter preceptivo la convocatoria de un período de

${ }^{26}$ En el mismo sentido, LÓPEZ-LAPUENTE, L., op. cit., pág. 835.

27 El artículo 86 LRJPAC establece lo siguiente:

«1. El órgano al que corresponda la resolución del procedimiento, cuando la naturaleza de éste lo requiera, podrá acordar un periodo de información pública.

2. A tal efecto, se anunciará en el Boletín Oficial del Estado, de la Comunidad Autónoma, o en el de la Provincia respectiva, a fin de que cualquier persona física o jurídica pueda examinar el procedimiento, o la parte del mismo que se acuerde.

El anuncio señalará el lugar de exhibición y determinará el plazo para formular alegaciones, que en ningún caso podrá ser inferior a veinte días.

3. La incomparecencia en este trámite no impedirá a los interesados interponer los recursos procedentes contra la resolución definitiva del procedimiento.

La comparecencia en el trámite de información pública no otorga, por sí misma, la condición de interesado. No obstante, quienes presenten alegaciones u observaciones en este trámite tienen derecho a obtener de la Administración una respuesta razonada, que podrá ser común para todas aquellas alegaciones que planteen cuestiones sustancialmente iguales.

4. Conforme a lo dispuesto en las Leyes, las Administraciones Públicas podrán establecer otras formas, medios y cauces de participación de los ciudadanos, directamente o a través de las organizaciones y asociaciones reconocidas por la Ley en el procedimiento de elaboración de las disposiciones y actos administrativos».

28 Por ejemplo, en materia de aprobación de planes urbanísticos. 
información pública. Al contrario, el carácter potestativo de la convocatoria del período de información pública no ofrece dudas a la vista de la literalidad del artículo 139.1 del Reglamento, que configura la apertura del período como hipotética y no mandatoria ( $C$ Cuando el Director de la AEPD acuerde, conforme a lo dispuesto en el artículo 86.1 LRJPAC...»). Por tanto, la apertura del período de información pública es potestativa para la AEPD, que habrá de hacerlo, según el artículo 86 LRJPAC, «cuando la naturaleza del procedimiento lo requiera».

El Reglamento podría haber seguido la opción de regular que los procedimientos de autorización de trasferencias internacionales, debido a su naturaleza, exigen en cualquier caso y con carácter general la apertura de un período de información pública. No lo ha hecho así, por lo que cabe preguntarse en qué supuestos la AEPD habrá de abrir el período de información pública.

Faltando una norma que exija, con carácter general, la apertura del trámite de información para los procedimientos de autorización de transferencias internacionales, la cuestión de su apertura habrá de resolverse por la AEPD caso por caso, a la vista de la finalidad del trámite que, tal y como señala la mejor doctrina, es «aportar al expediente puntos de vista inicialmente desconocidos y sacar a la luz intereses cuya existencia se presume, pero que no es posible identificar a priori» ${ }^{29}$.

Desde nuestro punto de vista, estos intereses a sacar a la luz durante el trámite de información pública han de estar relacionados con la protección de datos y no pueden consistir en intereses generales ajenos a ésta, como por ejemplo, el cumplimiento de la normativa laboral. En efecto, la información que se pretende incorporar al expediente mediante el trámite de información pública ha de resultar útil a efectos de la resolución del expediente (no se ha de tratar de cuestiones ajenas a la materia del expediente o de materias que, relacionadas con ésta, son irrelevantes a efectos de la decisión que haya de adoptar la AEPD).

Por ello, la aparente voluntad del Gobierno y la AEPD de configurar el trámite de información pública hacia el cumplimiento de obligaciones establecidas en ramas de nuestro ordenamiento distintas de la protección de datos, como la laboral — véase el apartado C de la

29 GARCÍA DE ENTERRÍA, E. Y FERNÁNDEZ, T.R., Curso de Derecho Administrativo, Volumen II, Décima Edición, Thomson-Civitas, Cizur Menor, Navarra, pág. 503. 
sección III. 2 de este artículo-, nos parece desafortunada, en cuanto supone una utilización instrumental de la normativa de protección de datos para fines del todo ajenos a ésta.

En cualquier caso y tal como se ha señalado, la AEPD viene siguiendo la práctica de convocar desde el año 2007 un período de información pública en relación con la generalidad de los procedimientos de autorización de transferencias internacionales, por lo que se podría deducir que la AEPD parece entender el trámite de información pública como necesario en cualquier caso.

(b) La AEPD publica el anuncio de la convocatoria del período de información pública en el Boletín Oficial del Estado, con un anuncio en el que identifica el solicitante y el procedimiento (no así el resto de circunstancias de la transferencia internacional - como, por ejemplo, el importador, país de destino y finalidad de la transferencia-), señala el lugar de exhibición (la sede la AEPD) y el plazo para formular alegaciones que, según el artículo 86.1 LRJPCA, no será inferior a veinte días ${ }^{30}$. Sin perjuicio de tal plazo general, es de señalar que el Reglamento establece un plazo específico, para el trámite de información pública de los procedimientos de autorización de transferencias internacionales, de diez días, que será por tanto el aplicable en estos supuestos.

${ }^{30} \mathrm{Vid}$., e.g, Res. AEPD por la que se procede a la publicación oficial del Acuerdo de Apertura del Período de Información Pública, número Expediente TI/00093/2007, que tiene la redacción siguiente: «En relación con el expediente [ ], por el que la entidad [ ], solicita autorización para la transferencia internacional de datos de carácter personal.

El Director de la Agencia Española de Protección de Datos, en el ejercicio de las competencias que le atribuye el artículo 37.1.l de la Ley Orgánica 15/1999, de 13 de diciembre, de Protección de Datos de Carácter Personal (LOPD), y con base en el artículo 86 de la Ley 30/1992, de 26 de noviembre, de Régimen Jurídico de las Administraciones Públicas y del Procedimiento Administrativo Común, acuerda:

Primero.-Abrir un periodo de información pública por un plazo de 20 días, a contar desde su publicación en el "Boletín Oficial del Estado», de conformidad con el artículo 86.1 de la Ley 30/1992, de 26 de noviembre, de Régimen Jurídico de las Administraciones Públicas y del Procedimiento Administrativo Común.

Segundo.-La documentación podrá examinarse y presentar las alegaciones que estime oportunas en las dependencias de la Agencia Española de Protección de Datos, calle Jorge Juan, $n .{ }^{\circ}$ 6, de Madrid, dentro del siguiente horario: de lunes a viernes de 9,30 h a $14 \mathrm{~h}$.

Contra este acuerdo no cabe interponer recurso alguno, sin perjuicio de la posibilidad de recurrir la resolución que ponga fin a este procedimiento.

Mediante este documento se notifica a [solicitante], el presente acuerdo, según lo exigido en el artículo 58.1 de la Ley 30/1992, de 26 de noviembre, de Régimen Jurídico de las Administraciones Públicas y del Procedimiento Administrativo Común.

Madrid, [fecha]. El Director de la Agencia Española de Protección de Datos. 
(c) La legitimación para formular alegaciones en el contexto de un trámite de información pública es muy amplia y está abierta a todos los administrados, sean o no interesados en sentido técnico (en este sentido, se ha llegado a hablar de «audiencia indiscriminada»).

Sin perjuicio de lo anterior y tal y como señala expresamente el artículo 86.3 LRJPAC «La comparecencia en el trámite de información pública no otorga, por sí misma, la condición de interesado.» La condición de interesado (y, por tanto, la titularidad de los derechos y facultades que a éstos concede nuestro ordenamiento administrativo) deriva de las circunstancias que identifica el artículo 31 LRJPAC (p.ej., la titularidad de derechos que puedan resultar afectados por la decisión que se adopte en el procedimiento) ${ }^{31}$, no de la mera formulación de alegaciones en el trámite de información pública ${ }^{32}$.

El único derecho que deriva de la formulación de alegaciones en el trámite de información pública es, tal y como señala el artículo 86.3 LRJPAC, el derecho a obtener de la AEPD una respuesta razonada. La AEPD habrá de tener presentes las alegaciones que se hagan pero no estará obligada a darles un valor determinado en la resolución del expediente. En este sentido, el Reglamento no exige la emisión de un informe específico sobre las alegaciones emitidas por terceros durante el trámite de información pública para proseguir la tramitación del procedimiento.

Ello plantea la cuestión del valor a otorgar a alegaciones de personas distintas de los afectados (únicos titulares del derecho fundamental y personalísimo a la protección de sus datos personales), como podría ser el caso, por ejemplo, de los sindicatos en relación

${ }^{31}$ El artículo 31 LRJPAC señala que: «1. Se consideran interesados en el procedimiento administrativo:

a) Quienes lo promuevan como titulares de derechos o intereses legítimos individuales o colectivos.

b) Los que, sin haber iniciado el procedimiento, tengan derechos que puedan resultar afectados por la decisión que en el mismo se adopte.

c) Aquéllos cuyos intereses legítimos, individuales o colectivos, puedan resultar afectados por la resolución y se personen en el procedimiento en tanto no haya recaído resolución definitiva.

2. Las asociaciones y organizaciones representativas de intereses económicos y sociales, serán titulares de intereses legítimos colectivos en los términos que la Ley reconozca. (...)».

32 En este sentido, el «exportador» es un «interesado» en relación con el procedimiento, pues lo ha promovido como titular de los derechos e intereses legítimos que nuestro ordenamiento le reconoce, en relación con las transferencias internacionales y, por tanto, el exportador tiene la condición de interesado en virtud del artículo 31.1.a) LRJPAC. 
con los datos de los trabajadores. De hecho, a nuestro conocimiento, los únicos casos de alegaciones realizadas hasta la fecha con ocasión del trámite de información pública de procedimientos de autorización de transferencias internacionales provienen de sindicatos de trabajadores, opuestos a las deslocalizaciones de servicios en el contexto de las cuales se enmarca la transferencia internacional de datos personales correspondiente ${ }^{33}$.

Desde nuestro punto de vista, el valor de las alegaciones que estas organizaciones puedan efectuar será muy limitado, a la vista de los intereses protegidos por los sindicatos ${ }^{34}$, el hecho de que los sindicatos no son "guardianes abstractos de la legalidad" ${ }^{35}$, el carácter personalísimo de los derechos de protección de datos (que excluye, salvo apoderamiento especial, su ejercicio por terceros - como son, a estos efectos, los sindicatos-) $)^{36}$ y el hecho de que, en principio, los sindicatos no tendrán la condición de «interesados» a efectos del procedimiento. ${ }^{37}$

33 Vid. Res. AEPD TI/00011/2007 y Res. AEPD TI/00017/2007.

${ }^{34}$ Es posible (y lógico) que las oposiciones de los sindicatos a las transferencias internacionales no guarden relación alguna con la protección de datos y los intereses que esta rama del ordenamiento protege, sino que persigan objetivos propios de tales organizaciones.

${ }_{35}$ La sentencia del Tribunal Constitucional 101/1996, de 11 de junio indica que: «la función constitucionalmente atribuida a los sindicatos no alcanza a transformarlos en guardianes abstractos de la legalidad, cualesquiera que sean las circunstancias en que ésta pretenda hacerse valer». Por su parte, la sentencia del Tribunal Constitucional 142/2004, de 13 de septiembre de 2004 señala que: «En definitiva, hemos señalado con reiteración que para poder considerar procesalmente legitimado a un sindicato no basta con que éste acredite la defensa de un interés colectivo o la realización de una determinada actividad sindical, dentro de lo que hemos denominado "función genérica de representación y defensa de los intereses de los trabajadores» (STC 101/1996, de 11 de junio, FJ 2). Debe existir, además, un vínculo especial y concreto entre dicho sindicato (sus fines, su actividad, etc.) y el objeto del debate en el pleito de que se trate, vínculo o nexo que habrá de ponderarse en cada caso y que se plasma en la noción de interés profesional o económico, traducible en una ventaja o beneficio cierto, cualificado y específico derivado de la eventual estimación del recurso entablado (SSTC 7/2001, de 15 de enero, FJ 5; y 24/2001, de 29 de enero, FJ 5)».

${ }^{36} \mathrm{La}$ AEPD señala en su página web (https://www.agpd.es/index.php?idSeccion=121): «El ejercicio del derecho de cancelación o rectificación es personalísimo, lo que significa que el titular de los datos deberá dirigirse directamente a dicha entidad, utilizando cualquier medio que permita acreditar el envío y la recogida de su solicitud, para el ejercicio de sus derechos...». Salvo apoderamiento, no se puede aceptar por tanto el ejercicio por un sindicato del derecho de protección de datos de sus afiliados.

37 No parece posible a priori que los sindicato puedan ostentar la condición de interesados a efectos de los procedimientos de autorización de transferencias internacionales, pues no han promovido los procedimientos (sólo el exportador está legiti- 
Por todo ello, si el objetivo del trámite de información pública que prevé el Reglamento es (como parece) la participación en el procedimiento de terceros ajenos a los intereses que protege el derecho fundamental a la protección de datos, la oportunidad de su instauración nos parece, cuanto menos, discutible. Si el legislador considera que los procesos de deslocalización han de estar sometidos a determinada publicidad, no tiene más que legislar en tal sentido pero no, indirectamente, modificar procedimientos administrativos ajenos a la materia.

(d) En el caso de que se hubieran formulado alegaciones en el trámite de información pública, el artículo 139.3 del Reglamento exige que se dé traslado de éstas al exportador, para que en un plazo de diez días alegue lo que estime procedente.

(e) Finalmente, el Reglamento excluye el acceso a expedientes en que concurran las circunstancias del artículo 37.5 LRJPAC.

El artículo 37 LRJPAC regula el derecho de acceso a archivos y registros, como manifestación del principio de transparencia que informa el procedimiento administrativo, y excluye en su apartado 5 tal derecho de acceso en relación con determinados tipos de expedientes, de los que sólo son relevantes a nuestros efectos «los relativos a las materias protegidas por el secreto comercial o industrial».

Determinada información del contrato correspondiente (distinta de las cláusulas contractuales tipo ${ }^{38}$ o incluida en sus anexos y relativa a circunstancias de la transferencia) pueda resultar sensible para una determinada empresa ${ }^{39}$. En tales casos y sobre la base del artículo 139.2 del Reglamento y 37.5 LRJPAC, el exportador solicitante de la autorización habrá de indicar a la AEPD qué información o documentación considera que constituye materia protegida por el secreto comercial o industrial y solicitar a ésta que excluya tal infor-

mado para ello — véase el apartado III.2 de este artículo-), ni tienen —a la vista de su objeto- derechos o intereses que puedan resultar afectados por la decisión que se adopte, teniendo en cuenta que, tal y como se ha señalado, los sindicatos no tienen entre sus funciones ser "guardianes abstractos de la legalidad» y el carácter personalísimo del derecho fundamental a la protección de datos.

38 En su inmensa mayoría, las solicitudes de autorización se basan en la firma de las cláusulas contractuales tipo previstas en las Decisiones comunitarias correspondientes y, por tanto y en tal medida, los contratos que se ponen a disposición de la AEPD para la autorización de las transferencias internacionales correspondientes tienen un clausulado predeterminado por tales Decisiones, por lo que difícilmente se podrá invocar su carácter confidencial.

39 Podría ser el caso, por ejemplo, de las circunstancias de una operación societaria de carácter confidencial que dé lugar a la transferencia internacional. 
mación o documentación para el caso de que decida convocar un período de información pública.

A modo de conclusión sobre las normas procedimentales que establece el Reglamento en relación con la instrucción de los procedimientos de autorización de transferencias internacionales de datos personales, creemos que la mera remisión a la LRJPAC en materia de período de información pública y de acceso a la documentación del expediente no es suficiente a efectos de conseguir el que parece ser objetivo primordial del Reglamento, esto es, garantizar la «necesaria seguridad jurídica ${ }^{40}$. Al contrario, tal remisión suscita numerosas dudas interpretativas, según se han apuntado, y ello porque el trámite de información pública que se ha incorporado al procedimiento no es apropiado para los fines que la Administración parece perseguir con su incorporación.

\section{III.4. Terminación del procedimiento}

El procedimiento terminará, en principio, mediante una Resolución acordando o denegando la transferencia internacional (si bien, también son posibles modos anormales de terminación del procedimiento como, por ejemplo, el desistimiento y la renuncia, de conformidad con la normativa general sobre el procedimiento administrativo contenida en la LRJPAC).

\section{A) Resolución}

La Resolución ha de cumplir con los requisitos generales de los actos administrativos y, en particular, ha de resultar motivada (artículo 54 LRJPAC).

\section{B) Duración del procedimiento}

Dentro de los límites que el artículo 42 LRJPAC establece en relación con la duración de los procedimientos administrativos ${ }^{41}$, el Re-

40 Apartado I de la Exposición de Motivos del Reglamento.

${ }^{41}$ El artículo 42 LRJPAC establece que: «2. El plazo máximo en el que debe notificarse la resolución expresa será el fijado por la norma reguladora del correspondiente procedimiento. Este plazo no podrá exceder de seis meses salvo que una norma con rango de Ley establezca uno mayor o así venga previsto en la normativa comunitaria europea. 
glamento ha optado por fijar la duración máxima del procedimiento de autorización de transferencias internacionales en tres meses (artículo 141.1 del Reglamento).

\section{C) Silencio administrativo positivo}

El artículo 140.1 del Reglamento señala que, en el caso de que no se hubiera resuelto y notificado en plazo la Resolución, se entenderá autorizada la trasferencia internacional. Ello se corresponde con la aplicación al supuesto de los procedimientos de autorización de transferencias internacionales de las reglas generales de nuestro ordenamiento sobre los efectos del «silencio administrativo» que, en este caso, conllevan un "silencio administrativo positivo». ${ }^{42}$

La estimación por silencio administrativo tiene a todos los efectos la consideración de acto administrativo finalizador del procedimiento, señala el artículo 43.3 LRJPAC, y la resolución expresa posterior a la producción del acto sólo podrá dictarse de ser confirmatoria del mismo.

La existencia del acto puede ser acreditada por cualquier medio de prueba admitido en Derecho, incluido el certificado acreditativo

3. Cuando las normas reguladoras de los procedimientos no fijen el plazo máximo, éste será de tres meses. Este plazo y los previstos en el apartado anterior se contarán:

En los procedimientos iniciados de oficio, desde la fecha del acuerdo de iniciación.

En los iniciados a solicitud del interesado, desde la fecha en que la solicitud haya tenido entrada en el registro del órgano competente para su tramitación".

${ }^{42} \mathrm{El}$ artículo 43 LRJPAC (sobre silencio administrativo en procedimientos iniciados a solicitud de interesado) establece que:

«1. En los procedimientos iniciados a solicitud del interesado, el vencimiento del plazo máximo sin haberse notificado resolución expresa legitima al interesado o interesados que hubieran deducido la solicitud para entenderla estimada o desestimada por silencio administrativo, según proceda, sin perjuicio de la resolución que la Administración debe dictar en la forma prevista en el apartado 4 de este artículo.

2. Los interesados podrán entender estimadas por silencio administrativo sus solicitudes en todos los casos, salvo que una norma con rango de Ley o norma de Derecho Comunitario Europeo establezca lo contrario. Quedan exceptuados de esta previsión los procedimientos de ejercicio del derecho de petición, a que se refiere el artículo 29 de la Constitución, aquellos cuya estimación tuviera como consecuencia que se transfirieran al solicitante o a terceros facultades relativas al dominio público o al servicio público, así como los procedimientos de impugnación de actos y disposiciones, en los que el silencio tendrá efecto desestimatorio.

No obstante, cuando el recurso de alzada se haya interpuesto contra la desestimación por silencio administrativo de una solicitud por el transcurso del plazo, se entenderá estimado el mismo si, llegado el plazo de resolución, el órgano administrativo competente no dictase resolución expresa sobre el mismo». 
del silencio producido que pudiera solicitarse a la AEPD (y que ésta habrá de emitir en un plazo máximo de quince días).

\section{REGLAS CORPORATIVAS VINCULANTES DEL ARTÍCULO 70.4 DEL REGLAMENTO}

\section{IV.1. Introducción: las reglas corporativas vinculantes}

Las «reglas corporativas vinculantes» (denominadas en inglés «binding corporate rules» y, en el artículo 137 del Reglamento «normas o reglas adoptadas en relación con el tratamiento de los datos en el seno del grupo») constituyen una de las formas (junto a, por ejemplo, las cláusulas contractuales tipo) en que el responsable del tratamiento puede ofrecer "garantías suficientes» que permitan la autorización de transferencias internacionales a destinatarios ubicados en países que no garanticen un nivel de protección adecuado. Esta posibilidad se dirige a grupos multinacionales, respecto de las transferencias internacionales a las sociedades del grupo que se encuentren ubicadas en países que no ofrecen un nivel de protección adecuado.

La posibilidad de otorgar reglas corporativas vinculantes a efectos de acreditar garantías suficientes no está expresamente prevista como tal en la Directiva 95/46/CE (más allá del régimen general del artículo 26 de la Directiva 95/46/CE) y ha ido tomando forma a través mediante varios documentos de trabajo del Grupo 29. Entre tales documentos de trabajo, destacaríamos los siguientes:

(a) el WP 74, de 3 de junio de 2003, relativo a la aplicación del artículo 26.2 de la Directiva 95/46/CE a las reglas corporativas vinculantes para las transferencias internacionales de datos (en adelante, «WP74»);

(b) el WP107, de 14 de abril de 2005, relativo a un procedimiento de cooperación en materia de reglas corporativas vinculantes (en adelante, «WP107»);

(c) el WP108, de 14 de abril de 2005, por el que se establece un modelo de cuestiones a tratar para solicitar la aprobación de reglas corporativas vinculantes (en adelante, «WP108») ${ }^{43}$; y

$43 \mathrm{El}$ antecedente de este documento es el documento del Grupo 29 WP102, de 25 de noviembre de 2004. 
(d) el WP133, de 10 de enero de 2007, relativo a un modelo de solicitud para la aprobación de reglas corporativas vinculantes (en adelante, «WP133»).

Además de las cuestiones de fondo que estas reglas corporativas vinculantes suscitan (que no son objeto de este artículo, limitado a los aspectos procedimentales), las reglas también plantean cuestiones procedimentales complejas. En efecto y a modo de ejemplo, la aprobación de tales reglas, debido a su naturaleza y fines, puede afectar a varias jurisdicciones comunitarias (de hecho, el WP107 establece un mecanismo de cooperación entre las distintas autoridades nacionales de protección de datos que se puedan ver afectadas).

En este contexto y como desarrollaremos a continuación, el Reglamento deja muchas (si no todas) de las cuestiones procedimentales sin resolver y, al contrario, suscita más incógnitas de las que el mecanismo de las reglas corporativas vinculantes, tal y como ha sido diseñado por el Grupo 29, suscita ya de por sí.

En cualquier caso, es de destacar que, tras la aprobación del Reglamento, el Grupo 29 elaboró los siguientes documentos de trabajo sobre reglas corporativas vinculantes, todos de fecha 24 de junio de 2008: (i) el WP153, por el que se establece un cuadro con los elementos y principios de las reglas corporativas vinculantes, (ii) el WP154, por el que se establece un marco para la estructura de las reglas corporativas vinculantes, y (iii) el WP155 sobre preguntas frecuentes en materia de reglas corporativas vinculantes.

\section{IV.2. Resumen del procedimiento de aprobación de las reglas corporativas vinculantes en los documentos de trabajo del Grupo 29}

Resumimos a continuación muy brevemente el procedimiento de aprobación de reglas corporativas vinculantes que el Grupo 29 propone en el WP107, cuando estas reglas afectan a varias jurisdicciones de la Unión Europea o Espacio Económico Europeo ${ }^{44}$.

${ }^{44}$ Las reglas corporativas vinculantes afectarán a varias jurisdicciones de la Unión Europea o Espacio Económico Europeo en la inmensa mayoría de los casos, sino en todos. En efecto, las reglas sólo afectarán a una jurisdicción cuando el grupo multinacional en cuestión únicamente realice transferencias internacionales a países sin protección adecuada desde un solo Estado de la Unión Europea o Espacio Económico Europeo. Sin embargo, si fuere este el caso, es dudoso que el grupo multinacional recurra a reglas corporativas vinculantes (en vez de a garantías como las cláusulas 
(a) El solicitante ha de dirigir su solicitud a la autoridad nacional de protección de datos que proponga a efectos de liderar el procedimiento de autorización de las reglas corporativas vinculantes (procedimiento que se basa en la cooperación entre autoridades nacionales de protección de datos) ${ }^{45}$. La solicitud ha de constar en el idioma de la mencionada autoridad y en inglés.

(b) Esta solicitud ha de incluir la información indicada en el modelo establecido en el WP133, que incluye en un primer apartado la información que justifica la elección de la autoridad nacional «líder», así como un borrador de las reglas corporativas vinculantes cuya aprobación se pretende. Asimismo, el solicitante ha de indicar qué partes de la solicitud tienen, en su opinión, carácter confiden$\mathrm{cial}^{46}$.

(c) La autoridad nacional «líder» circula entre el resto de autoridades nacionales la parte de la solicitud relativa a su designación como «líder», para el caso de que hubiera objeciones por parte de éstas.

(d) Una vez la autoridad nacional «líder» definitivamente fijada, el borrador de reglas corporativas vinculantes es discutido entre ésta y el solicitante y circulado a las autoridades nacionales afectadas, a efectos de sus comentarios.

(e) Una vez incorporados los comentarios de las distintas autoridades nacionales, la autoridad nacional «líder» circula la versión final de las reglas corporativas vinculantes al resto de autoridades nacionales (esta versión final ha de traducirse al idioma de las autoridades nacionales afectadas). En el caso de que las autoridades nacionales estén conformes, así lo indicarán y tal conformidad supondrá su acuerdo a otorgar las autorizaciones que la normativa nacional exija en relación con las transferencias internacionales en cuestión.

Es de destacar que, tal y como el sistema aparece diseñado por el Grupo 29, la aprobación de las reglas corporativas vinculantes por

contractuales tipo aprobadas por la Comisión), pues una de las principales razones para recurrir a reglas corporativas vinculantes es precisamente simplificar el procedimiento de autorización cuando son varias las autoridades nacionales que han de conocer de las transferencias internacionales de un grupo multinacional.

45 El WP107 propone varios criterios para la determinación de la autoridad nacional competente, siendo el criterio preferente la ubicación de la sede principal del grupo en Europa, si bien existe cierta flexibilidad en la determinación de la autoridad.

${ }^{46}$ Cada autoridad nacional decidirá, en función de su legislación nacional, qué tratamiento dar a la información y documentación indicada como confidencial por el solicitante. En el caso español, la cuestión se regirá por el artículo 37.5 LRJPAC. 
una autoridad nacional no elimina la obligación, para el solicitante o las sociedades de su grupo correspondientes, de obtener las autorizaciones de transferencias internacionales exigidas en cada jurisdicción ${ }^{47}$.

Por ejemplo, para el caso de que la autoridad nacional del Reino Unido aprobara una reglas corporativas vinculantes que incluyan transferencias internacionales desde España a países sin protección adecuada, la sociedad del grupo responsable de los ficheros que se fueran a transferir desde España habría de solicitar la autorización de estas transferencias internacionales a la AEPD (si bien, en el caso de que la AEPD haya otorgado su conformidad a la versión final de las reglas corporativas aprobadas, en nuestro ejemplo, por la autoridad del Reino Unido, la AEPD se encontrará obligada a otorgar la autorización).

\section{IV.3. Postura de la AEPD y Reglamento en relación con el procedimiento de las reglas corporativas vinculantes}

El Reglamento admite la posibilidad de autorizar transferencias internacionales sobre la base de reglas corporativas vinculantes en su artículo $70.4^{48}$. Este dato es ya de por sí relevante, pues las autoridades nacionales no se encuentran obligadas a reconocer virtualidad a las reglas corporativas vinculantes $\mathrm{y}$, a la vista de este contenido del Reglamento, la AEPD ha decidido hacerlo.

En relación con los aspectos procedimentales en la materia, el Reglamento señala en el último párrafo de su artículo 137 que «Si la autorización se pretendiera fundar en lo dispuesto en el apartado 4 del artículo 70 [las reglas corporativas vinculantes], deberán aportarse las

47 Así lo interpreta la autoridad nacional francesa (CNIL) en su documento "Transferts de données à caractère personnel vers des pays non membres de l'Unnion européenne» (Transferencias de datos de carácter personal a países no miembros de la Unión Europea) de enero de 2007.

${ }^{48} \mathrm{El}$ artículo 70.4 del Reglamento señala que: «También podrá otorgarse la autorización para la transferencia internacional de datos en el seno de grupos multinacionales de empresas cuando hubiesen sido adoptados por los mismos normas o reglas internas en que consten las necesarias garantías de respeto a la protección de la vida privada y el derecho fundamental a la protección de datos de los afectados y se garantice asimismo el cumplimiento de los principios y el ejercicio de los derechos reconocidos en la Ley Orgánica 15/1999, de 13 de diciembre, y el presente Reglamento.

En este caso, para que proceda la autorización del Director de la Agencia Española de Protección de Datos será preciso que las normas o reglas resulten vinculantes para las empresas del Grupo y exigibles conforme al ordenamiento jurídico español». 
normas o reglas adoptadas en relación con el tratamiento de los datos en el seno del grupo, así como la documentación que acredite su carácter vinculante y su eficacia dentro del grupo. Igualmente deberá aportarse la documentación que acredite la posibilidad de que el afectado o la Agencia Española de Protección de Datos puedan exigir la responsabilidad que corresponda en caso de perjuicio del afectado o vulneración de las normas de protección de datos por parte de cualquier empresa importadora».

Ésta es la única referencia que el Reglamento hace al procedimiento de aprobación de las reglas corporativas vinculantes, y a la concesión de autorizaciones para transferencias internacionales sobre la base de éstas. A la vista de la anterior, surgen numerosas cuestiones sobre la interpretación de tal precepto:

(a) No es claro si el articulo 137.4 del Reglamento se aplica a (i) la aprobación de reglas corporativas vinculantes por la AEPD (en cuanto autoridad nacional «líder»), (ii) la autorización de transferencias internacionales por la AEPD sobre la base de reglas corporativas vinculantes aprobadas por una autoridad nacional distinta de la AEPD, o (iii) la autorización de transferencias internacionales por la AEPD sobre la base reglas corporativas vinculantes a aprobar en un mismo procedimiento por la AEPD (en cuanto autoridad nacional «líder»).

Del contenido general del artículo 137.4 del Reglamento y su ubicación sistemática parece deducirse que hace referencia al contenido de las solicitudes de autorización de transferencias internacional y que, por tanto, estamos en el supuesto indicado bajo (ii) o (iii). Sin embargo, si se estuviera en el supuesto indicado bajo (ii), no tiene sentido exigir la documentación necesaria para examinar de nuevo las reglas corporativas vinculantes (ya aprobadas por una autoridad nacional extranjera, con la conformidad de la AEPD), y si se estuviera en el supuesto indicado bajo (iii), la regulación ignora por completo la complejidad del caso, pues la AEPD habría de recurrir al mecanismo de coordinación con el resto de autoridades nacionales.

(b) En cualquier caso, el Reglamento no hace referencia alguna al procedimiento de coordinación entre autoridades nacionales (tanto para el caso de un procedimiento iniciado en el extranjero como para el caso de un procedimiento que se inicie ante la AEPD), por lo que surge la cuestión de cómo se va a arbitrar éste por la AEPD en nuestro país. Entendemos que la AEPD funcionará de acuerdo con los documentos de trabajo del Grupo 29 que se han mencionado en el apartado IV.1 (y que no tienen el carácter de normas), si bien la aprobación del Reglamento hubiera sido una ocasión perfecta para 
regular el procedimiento aplicable y asegurar la necesaria seguridad jurídica para la aprobación de reglas corporativas vinculantes en nuestro país.

(c) En relación con la documentación a aportar, el artículo 137.4 del Reglamento exige la «documentación que acredite su carácter vinculante [de las reglas corporativas] y su eficacia dentro del grupo», así como «la documentación que acredite la posibilidad de que el afectado o la Agencia Española de Protección de Datos puedan exigir la responsabilidad que corresponda en caso de perjuicio del afectado o vulneración de las normas de protección de datos por parte de cualquier empresa importadora».

Desde nuestro punto de vista y si bien la redacción del Reglamento al respecto no resulta afortunada, la documentación exigida coincidirá con la documentación e información descritas en los documentos de trabajo del Grupo 29 y, en particular, en los documentos WP108 y WP133. En este sentido y a pesar de la redacción abierta del precepto ("cualquier empresa importadora»), entendemos que la acreditación de la posibilidad de exigencia de responsabilidad por afectados españoles y la AEPD se refiere a los casos de perjuicios o vulneraciones que tengan por objeto transferencias desde España (y no la totalidad de las transferencias internacionales previstas por las reglas corporativas vinculantes, salvo que la AEPD funcione en el caso concreto como autoridad nacional «líder»).

\section{IV.4. Conclusión}

El Reglamento ha perdido la ocasión de aportar seguridad jurídica y favorecer los mecanismos para la aprobación de las reglas corporativas vinculantes ${ }^{49}$. Al contrario, las reglas procedimentales que aporta no tratan con un mínimo de rigor y desarrollo las cuestiones que el sistema de las reglas corporativas vinculantes plantea.

En este sentido, habrá que estar a la práctica que la AEPD decida adoptar, sin base legal precisa (fuera de los documentos de trabajo del Grupo 29, que no tienen el carácter de normas jurídicas).

No tenemos conocimiento que, a la fecha de este artículo, la AEPD esté conociendo de procedimientos para la aprobación de re-

49 A la misma conclusión llega ÁLVAREZ RIGAUDIAS, C. en op. cit., página 539: «Hubiera sido deseable que se aprovechara el Reglamento para establecer cómo utilizar de forma efectiva y ágil este instrumento [las reglas corporativas vinculantes]». 
glas corporativas iniciados ante ésta ${ }^{50}$. Sin perjuicio de lo anterior, es de destacar que la autoridad británica de protección de datos (el I.C.O. -Information Commissioner's Office-) ha aprobado reglas corporativas en, al menos, dos ocasiones. Es el caso de las reglas corporativas vinculantes de los grupos multinacionales General Electric $^{51}$ y Philips ${ }^{52}$. Respecto de este último, el I.C.O. señala en la nota de prensa correspondiente su colaboración con otras autoridades nacionales europeas de protección de datos.

\section{PROCEDIMIENTO DE SUSPENSIÓN TEMPORAL DE TRANSFERENCIAS INTERNACIONALES DE DATOS}

En el presente epígrafe $\mathrm{V}$, analizaremos el procedimiento de suspensión temporal de transferencias internacionales de datos personales (incluido el levantamiento de tal suspensión), regulado en la sección segunda del Capítulo V del Título IX del Reglamento (artículos 141 a 144, ambos inclusive).

\section{V.1. Objeto del procedimiento}

El procedimiento en cuestión tiene por objeto la suspensión temporal de transferencias internacionales de datos personales y se prevé para los siguientes supuestos:

(a) los supuestos del artículo 69 del Reglamento, esto es, las transferencias a importadores ubicados en un tercer Estado del que se haya declarado la existencia de un nivel adecuado de protección, en determinadas circunstancias (señaladas en el artículo 69 del Reglamento).

(b) los supuestos previstos en el apartado 3 del artículo 70 del Reglamento, esto es, transferencias a importadores ubicados en Estados que no proporcionen un nivel adecuado de protección, en determinadas circunstancias (señaladas en el apartado 3 del artículo 70 del Reglamento).

50 La Memoria de la AEPD de 2008 no menciona procedimientos de esta clase.

51 Vid. Resolución de 15 de diciembre de 2005 del I.C.O. publicada en la siguiente dirección de Internet: http://www.ico.gov.uk/upload/documents/library/ data_protection/ detailed_specialist_guides/binding_corporate_rules_authorisation \% 20_final.pdf

${ }_{52} \mathrm{Vid}$. Nota de prensa del I.C.O. de 9 de mayo de 2007 publicada en la siguiente dirección de Internet: http://www.ico.gov.uk/upload/documents/pressreleases/ 2007/philips_authorised_by_ico_to_transfer_personal_information\%E2\%80\%A6.pdf. 
Los supuestos que se han indicado bajo la letra (a) coinciden con los del apartado 2 de la Norma Cuarta de la Instrucción 1/2000 y los indicados bajo la letra (b) con los del apartado 7 de la Norma Quinta de la Instrucción $1 / 2000^{53}$.

El procedimiento no tiene por objeto perseguir una infracción del ordenamiento jurídico por el acto de autorización de la transferencia internacional, declarándolo nulo, sino aprobar un nuevo acto administrativo, diferenciado del acto de autorización.

\section{V.2. Iniciación}

De conformidad con el artículo 141.1 del Reglamento, el procedimiento se iniciará por el Director de la AEPD, mediante un acuerdo motivado y fundado en los mencionados supuestos.

Tal y como señala el artículo 69 LRJPAC para el caso de los procedimientos iniciados de oficio, la iniciación puede ser por propia iniciativa de la Administración (en este caso, la AEPD), a petición razonada de otros órganos o por denuncia.

\section{V.3. Instrucción y resolución}

Las únicas reglas de procedimiento que establece el Reglamento en relación con la instrucción del procedimiento son las siguientes:

(a) La AEPD dará traslado del acuerdo de iniciación al exportador para que alegue lo que a su derecho convenga (artículo 142.1 del Reglamento). Ello es consustancial al carácter contradictorio que informa los procedimientos administrativos y al carácter de interesado del exportador en el procedimiento. Por ello, el exportador dispondrá de todos los derechos que nuestro ordenamiento administrativo reconoce a los interesados, incluida el derecho a impugnar la resolución final.

(b) Recibidas las mencionadas alegaciones o transcurrido el plazo para formularlas, la AEPD resolverá.

53 A diferencia de otros contenidos de la Instrucción 1/2000, las mencionadas Normas no fueron declaradas nulas por la Audiencia Nacional (Sala de lo Contencioso-Administrativo, Sección Primera) en su sentencia de 15 de marzo de 2002, confirmada por la sentencia del Tribunal Supremo (Sala de lo Contencioso-Administrativo, Sección Sexta) de 25 de septiembre de 2006. 
Sin perjuicio de la parquedad de la regulación del presente procedimiento, es necesario recordar la aplicación supletoria de la LRJPAC. En este sentido, en el supuesto de que la AEPD no tuviera por ciertos los hechos alegados por el exportador, debería abrirse un período de prueba a fin de esclarecer los hechos.

\section{V.4. Levantamiento de la suspensión temporal}

El Reglamento señala muy parcamente que: «La suspensión se levantará tan pronto como cesen las causas que la hubieran justificado, mediante resolución del Director de la Agencia Española de Protección de Datos, del que se dará traslado al exportador».

Los perfiles del «levantamiento» de la suspensión y el procedimiento a estos efectos no son del todo nítidos, aunque parece claro que no se trata de la revocación del acto administrativo de suspensión mediante su anulación (no estamos, en la lógica del precepto, frente a una infracción del ordenamiento jurídico por el acto de suspensión), sino de la formulación de un nuevo acto administrativo, que - ante el silencio del Reglamento- la AEPD habrá de adoptar de acuerdo con las reglas generales de procedimiento de la LRJPAC, iniciándose el procedimiento en cuestión bien de oficio por la AEPD (en este supuesto parece pensar el Reglamento), bien a instancia del exportador.

En este sentido y desde el punto de vista del principio de contradicción que ha de informar los procedimientos administrativos, parece criticable que el Reglamento conciba el procedimiento de levantamiento de la suspensión como un procedimiento sin participación alguna del exportador (la resolución correspondiente se le notifica sin más), cuando éste tiene claramente la condición de interesado a efectos del procedimiento.

\section{INSCRIPCIÓN EN EL REGISTRO GENERAL DE PROTECCIÓN DE DATOS}

Las Resoluciones resultantes de los procedimientos relacionados con las transferencias internacionales de datos personales son objeto de inscripción en el Registro General de Protección de Datos de la AEPD. Es el caso de las siguientes resoluciones en virtud del artículo 116.1 del Reglamento y de los artículos del mismo que se citan a continuación: 
(a) las autorizaciones de las transferencias internacionales de datos personales, en virtud del artículo 139.1 del Reglamento;

(b) las suspensiones temporales de las transferencias internacionales de datos personales, en virtud del artículo 143.1 del Reglamento; y

(c) el levantamiento de las suspensiones temporales de las transferencias internacionales de datos personales, en virtud del artículo 144.2 del Reglamento.

En todos los casos, es la propia AEPD la que ha de dar traslado de las Resoluciones al Registro General de Protección de Datos, que inscribirá de oficio el acto en cuestión (artículos 139.1, 143.1 y 144.2 del Reglamento). No es necesario por tanto una notificación específica del responsable del fichero a la AEPD, solicitando a ésta que modifique el apartado de transferencias internacionales de la inscripción del fichero en el Registro General de Protección de Datos.

Cualquier persona puede conocer, mediante la consulta del Registro General de Protección de Datos — que es pública y gratuita-, las circunstancias del tratamientos de datos de carácter personal, incluidas las transferencias internacionales correspondientes, por lo que se asegura de esta forma su publicidad.

En relación con la publicidad de las resoluciones, es de destacar asimismo que, de conformidad con el artículo 116.2 del Reglamento (que desarrolla el artículo 37.2 LOPD), éstas se insertarán en la página web de la AEPD.

\section{NOTIFICACIONES EXIGIDAS POR LA NORMATIVA COMUNITARIA}

La Directiva 95/46/CE establece obligaciones de información por parte de los Estados miembros a la Comisión, en relación con la actividad de control de las transferencias internacionales por parte de aquéllos. En este sentido, el artículo 26.3 de la Directiva 95/46/CE señala que los Estados miembros informarán a la Comisión y los demás Estados miembros sobre las autorizaciones de transferencias internacionales que concedan ${ }^{54}$.

${ }^{54}$ El artículo 26.3 de la Directiva 95/46/CE establece que «Los Estados miembros informarán a la Comisión y a los demás Estados miembros acerca de las autorizaciones que concedan con arreglo al apartado 2. Por su parte, el artículo 25.3 de la misma Directiva señala que los Estados miembros se informarán recíprocamente sobre los casos en que consideren que un tercer país no garantiza un nivel de protección adecuado". 
En este contexto, el Reglamento ha establecido la obligación de notificar las siguientes resoluciones al Ministerio de Justicia, para que proceda a su notificación a la Comisión Europea y a los demás Estados miembros, en cumplimiento al artículo 26.3 de la Directiva 95/46/CE:

(a) las Resoluciones de concesión o denegación de transferencias internacionales (artículo 139.2 del Reglamento);

(b) las Resoluciones de suspensión de transferencias internacionales (artículo 143.2 del Reglamento); y

(c) las Resoluciones de levantamiento de la suspensión de transferencias internacionales (artículo 144.3 del Reglamento).

El Reglamento señala por tanto al Ministerio de Justicia como el órgano de la Administración General del Estado competente para realizar la comunicación a la Comisión Europea y demás Estados miembros, comunicación que habrá de realizarse en el plazo del artículo 10 LRJPAC ${ }^{55}$.

\section{RECURSOS CONTRA LAS RESOLUCIONES}

El Reglamento no hace mención expresa a los recursos disponibles frente a las Resoluciones de la AEPD en materia de transferencias internacionales, por lo que es aplicable el régimen general.

Las Resoluciones en materia de transferencias internacionales pueden ser objeto, en particular, de los siguientes recursos:

(a) recurso potestativo de reposición ante el Director de la AEPD en el plazo de un mes desde la notificación de la Resolución ${ }^{56} ; \mathrm{y}$

(b) recurso contencioso-administrativo ante la Sala de lo Contencioso-Administrativo de la Audiencia Nacional, en el plazo de dos meses desde la notificación de la Resolución ${ }^{57}$.

55 El artículo 10 LRJPAC establece, en relación con las comunicaciones a las Comunidades Europeas, que: «1. Cuando en virtud de una obligación derivada del Tratado de la Unión Europea o de los Tratados de las Comunidades Europeas o de los actos de sus instituciones deban comunicarse a éstas disposiciones de carácter general o resoluciones, las Administraciones públicas procederán a su remisión al órgano de la Administración General del Estado competente para realizar la comunicación a dichas instituciones. En ausencia de plazo específico para cumplir esa obligación, la remisión se efectuará en el de quince días. 2. Cuando se trate de proyectos de disposiciones o cualquiera otra información, en ausencia de plazo específico, la remisión deberá hacerse en tiempo útil a los efectos del cumplimiento de esa obligación».

56 Vid. los artículos 116 y 117 LRJPAC.

57 Vid. los artículos 25 y 46.1 de la Ley 29/1998, de 13 de julio, reguladora de la Jurisdicción Contencioso-administrativa, y apartado 5 de su disposición adicional cuarta. 


\section{CONCLUSIÓN}

La valoración de la regulación especial de los procedimientos en materia de transferencias internacionales es en general positiva, en cuanto redunda en una mayor seguridad jurídica en relación con el régimen de los procedimientos administrativos relativos a transferencias internacionales.

Sin embargo y tal y como se ha desarrollado en el presente artículo, el Reglamento ha perdido en ocasiones la oportunidad de enfrentarse a las particularidades de la materia que podían aconsejar particularidades procedimentales y de regularlas con el alcance y precisión exigidos. Es el caso, por ejemplo, de los supuestos en que el Reglamento hace una remisión sin más a las reglas generales del procedimiento (que, por tanto, es innecesaria, en cuanto no afronta las particularidades del caso y deja éstas al arbitrio de la AEPD) y, sobre todo, de las normas procedimentales sobre la aprobación de reglas corporativas vinculantes (materia en la que, como hemos visto, el Reglamento ha optado por ignorar por completo su complejidad procedimental).

\section{BIBLIOGRAFÍA}

AAVV, Comentario al Reglamento de desarrollo de la Ley Orgánica 15/1999, de 13 de diciembre, de Protección de Datos de Carácter Personal (aprobado por RD 1720/2007, de 21 de diciembre), Thomson Civitas, Cizur Menor 2008.

AAVV, La nueva Ley de Régimen Jurídico de las Administraciones Públicas y del Procedimiento Administrativo Común, Tecnos, Madrid, 1993.

AGENCIA ESPAÑOLA DE PROTECCIÓN DE DATOS, Memorias 2008, 2007 y 2006.

APARICIO SALOM, J., Estudio sobre la Ley Orgánica de Protección de Datos de Carácter Personal, Aranzadi, Elcano 2000.

ARENAS RAMIRO, M.: El derecho fundamental a la protección de datos de carácter personal en Europa, Tirant lo Blanch, Valencia 2006.

DÍEZ DE VELASCO, M., Las organizaciones internacionales, Tecnos, 15. ${ }^{\mathrm{a}}$ ed., Madrid 2008.

GARCÍA DE ENTERRÍA, E. y FERNÁNDEZ T. R., Curso de Derecho Administrativo, 10. ${ }^{\mathrm{a}}$ ed., Thomson-Civitas, Cizur Menor, Navarra 2007. 
GONZÁLEZ PÉREZ, J. y GONZÁLEZ NAVARRO, F., Comentarios a la Ley de Régimen Jurídico de las Administraciones Públicas y del Procedimiento Administrativo Común (Ley 30/1992 de 26 de noviembre), Thomson-Civitas, 3. ${ }^{\mathrm{a}}$ ed., Madrid 2003.

MARTÍNEZ MARTÍNEZ, R., Protección de Datos. Comentarios al Reglamento de Desarrollo de la LOPD, Tirant Lo Blanch, Valencia 2008.

MANGAS MARTÍN, A. y LIÑÁN NOGUERAS, D., Instituciones y Derecho de la Unión Europea, Tecnos, 5. ${ }^{\mathrm{a}}$ ed., Madrid 2007.

PARADA VÁZQUEZ, J. R., Derecho Administrativo, 3 volúmenes, Marcial Pons, 14. ${ }^{\text {a }}$ ed., Madrid 2002.

PAREJO ALONSO, R., Derecho administrativo, Ariel, Madrid 2003.

REBOLLO DELGADO, L., Vida privada y protección de datos en la Unión Europea, Dikynson S.L., Madrid 2008.

SANTAMARÍA PASTOR, J. A., Principios de Derecho Administrativo, Editorial Centro de Estudios Ramón Areces, 2. a ed., Madrid 1998. 